NICAISE I., SCHOCKAERT I. (2014), The hard-to-reach among the poor in Europe: lessons from Eurostat's EU-SILC survey in Belgium, in TOURANGEAU R. EDWARDS B., JOHNSON T., WOLTER K., BATES N. (eds., 2014), Hard-to-survey populations, Cambridge University Press, p.1246-1279

\title{
26
}

\section{The hard to reach among the poor in Europe: lessons from Eurostat's EU-SILC survey in Belgium}

\author{
IDES NICAISE AND INGRID SCHOCKAERT
}

Every year the European (and Belgian) authorities publish figures concerning poverty and precariousness, based on the EU Surveys of Income and Living Conditions (EU-SILC). These surveys are carried out jointly by the statistical offices of the member states and coordinated by Eurostat. From these, it can be seen that the at-risk-of-poverty rate (AROP) in the EU for the year 2011 was 16.9 percent (European Commission, 2013). The income threshold used to define the AROP rate is set separately for each member state at 60 percent of the median equalized disposable income in the country, ${ }^{1}$ and the EU average is weighted by the population size. Despite widespread consensus on the validity of this AROP rate, new problems arose with the extension of the EU in 2004. In the new member states from Central and Eastern Europe, the average standard of living was so low that the 60 percent norm looked unrealistically low. ${ }^{2}$ Therefore, two additional poverty criteria were introduced, namely, a material deprivation index (based on a list of necessities) and joblessness at household level. Households meeting any of the three criteria are called "at-risk-of-povertyand-social-exclusion" (AROPE). Incorporating these criteria, the extended poverty rate for the EU was 24.1 percent in 2011, affecting 119.5 million people (European Commission, 2013). All three criteria are measured by means of EU-SILC. The importance of these indicators is also reflected in the Europe 2020 strategy, which aims (among other targets) to reduce poverty (based on the AROPE criterion) by 20 million individuals.

Apart from the three key indicators discussed above, EU-SILC produces data for a wider set of indicators relating to education, housing, health, etc. (the so-called Laeken indicators), which allow for a multidimensional comparison of poverty and living conditions (see, e.g., European Commission, 2013). Moreover, the survey is a "rotating panel," with one quarter of the sample being renewed every year. In other words, every household forms part of the sample for between one and three years, which allows limited longitudinal analyses to be performed.

Research funded within the context of the AGORA research program of the Belgian Federal Science Policy Office (BELSPO) and at the request of the Combat Poverty, Insecurity, and Social Exclusion Service

1 Equivalized income is the income per consumption unit, using the modified OECD equivalence scales to make income comparable across household types.

2 The average disposable income in countries such as Bulgaria or Romania is barely one third of the average in rich Western member states. 
Despite the wealth of information that can be extracted from the EU-SILC, further problems arise with the poverty measures, which are attributable to the difficulty in reaching the poor in general. For this reason, the Belgian Combat Poverty Service ${ }^{3}$ commissioned research on the gaps and potential quality improvements in these poverty statistics for Belgium. The purpose of this research can be summarized in three main points: (1) an analysis of the selective nonresponse from groups that are included in the EU-SILC; (2) an identification of groups with a relatively high poverty risk that for various reasons were not included in the EU-SILC; and (3) a complementary pilot survey on the living conditions of some of those "forgotten groups of poor people."

\subsection{Selective nonresponse in the EU-SILC}

Are poor households hard to reach? The answer to this question is complex and ambivalent. Some research suggests that it is easier to gain cooperation from poor populations than from the wealthy, especially at the initial contact - they are more compliant, willing to cooperate with authorities. Yet, De Keulenaer and Levecque (2004), Groves and Couper (1998), and Heerweegh, Abts and Loosveldt (2007) found enhanced nonresponse rates among lowincome groups, due to characteristics that correlate with poverty rather than low income per se (immigrants, single persons, single parents, inner city inhabitants, and tenants). Using Tourangeau's typology in Chapter 1, this volume, we would argue that poor households are not hard to sample or hard to contact in general. However, some specific subgroups, such as homeless people, are hard to sample; others are also hard to contact, such as undocumented immigrants; still others may be hard to interview, due to language barriers (newly arrived immigrants) or low literacy (low-educated people).

The first objective of our research was to examine in greater detail the determinants of selective nonresponse in the EU-SILC survey, particularly among poor households. This nonresponse has various levels and forms:

- As in most cross-section surveys, a basic distinction is made between unit nonresponse (a household that does not respond) versus item nonresponse (no answer to specific questions).

- Unit nonresponse may be attributable to unreachability (e.g., because the address is incorrect or the household is repeatedly absent), refusal, or to interruption or uselessness of the interview (e.g., too many missing values, inconsistencies etc.).

- As EU-SILC is a rotating panel, a further distinction can be made between initial nonresponse (at first contact) versus attrition (nonresponse during a subsequent wave as part of the panel).

In the EU-SILC, little is known about the bias that may be associated with nonresponse in the first wave. The overall nonresponse rate was approximately 40 percent; slightly less than

3 The full name is Resemree Centre for the Fight against Poverty, Insecurity, and Social Exclusion (www. combatpoverty.be): this service, created by law, supports a permanent dialogue between all stakeholders in the fight against poverty and produces recommendations and evaluations of the policies conducted in this field. 
half of this was attributable to refusals. We assume the nonresponse rate among poor households is higher, in part because of language barriers among immigrants, and also for the reasons mentioned above. The potential bias in the first wave of EU-SILC has not yet been fully examined by the Belgian statistical office (ADSEI). Although only limited information is available for analysing this issue, it appears to be possible and desirable to examine the data that could shed light on bias. For all households, ADSEI has access to (a) basic information from the National Register ${ }^{4}$ (age, sex, nationality, occupation, civil status, etc.) and (b) an address. ADSEI calculated nonresponse rates based on the variables included in the National Register only. However, addresses could have been linked to socioeconomic profile data about the statistical sector (neighborhood) in which this address is located. In this way, patterns of nonresponse by socioeconomic background could have been mapped in a better way. Unfortunately, due to a combination of restricted access to National Register data and understaffing of ADSEI, we were unable to carry out this analysis during our research project.

However, we are able to analyse attrition in detail because this involves households that have participated during a given wave but no longer participated in a subsequent wave for some reason. One may obviously speculate why some households (including the poor in particular) would start participating in a panel and drop out later. In the initial sample, overall nonresponse is typically higher than in subsequent waves, but we see no reason why the patterns of nonresponse would differ between waves. On the contrary, we can learn a lot about selective nonresponse from the analysis of attrition because very detailed information is available from the previous wave about these households. We can also study the determinants by "type" of nonresponse (unreachability, refusal, or interruption of the interview). Table 26.1 shows overall nonresponse in Wave 2 by type, and Table 26.2 shows the results of our logistic regression models.

The most striking finding in Table 26.1 is the relatively high rate of break offs during the interviews (14.4 percent), compared to other CAPI surveys. This may be attributable to the long duration of interviews and complexity of the questionnaires. The section devoted to

Table 26.1 Overall attrition in EU-SILC Wave 2 (2005) by type of nonresponse

\begin{tabular}{lrr}
\hline & $\mathrm{n}$ & $\%$ \\
\hline (Repeated) attempt at contact $^{a}$ & 4052 & \\
Contact failure (Household unreachable) & 38 & 0.94 \\
Refusal & 495 & 12.33 \\
Interrupted interview, unreliable answers & 506 & 12.61 \\
Successful interview & 3013 & 75.06 \\
\hline
\end{tabular}

${ }^{a}$ The number of missing values for this variable was substantial (98 observations).

4 The samples for EU-SILC are drawn from the National Register. 


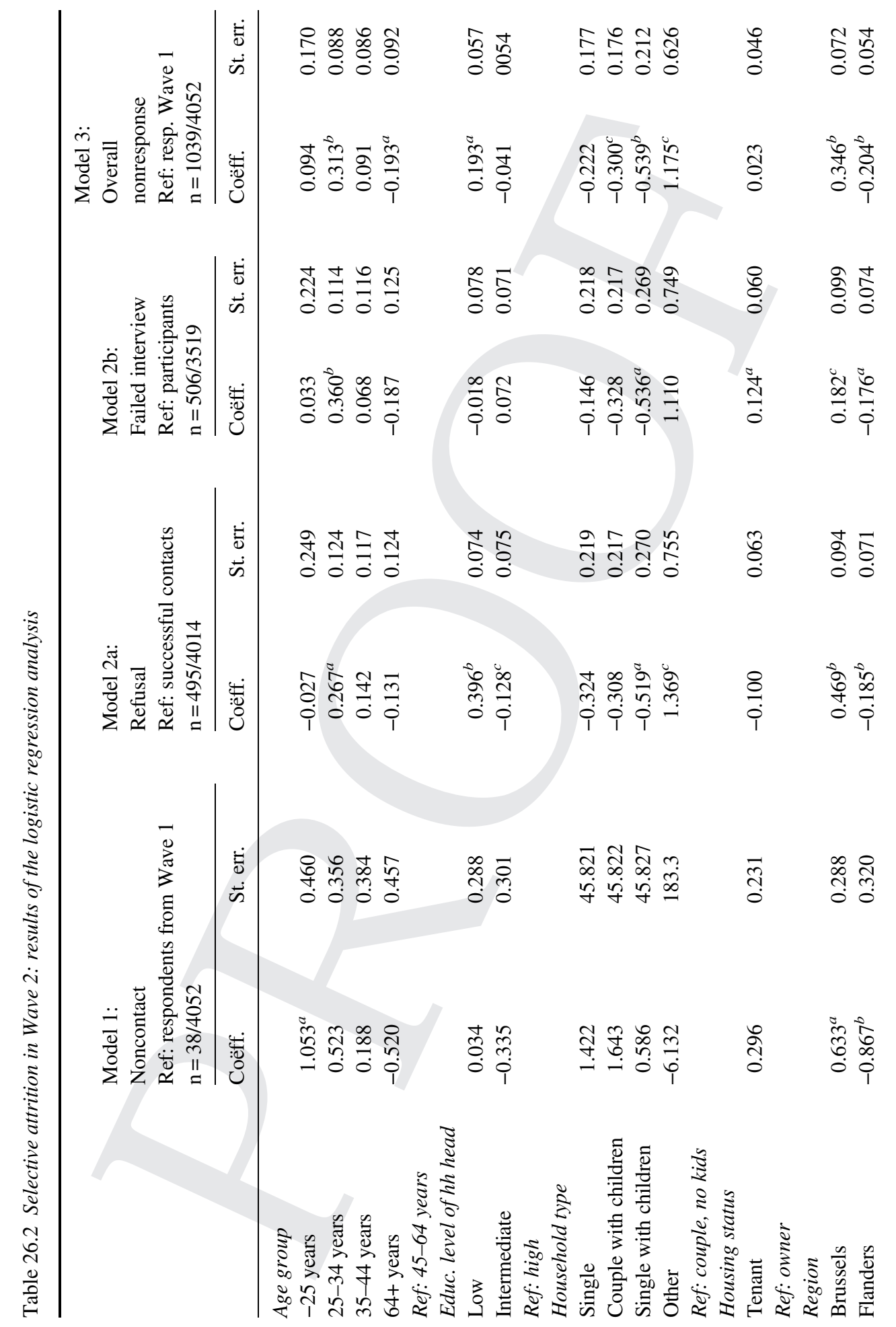




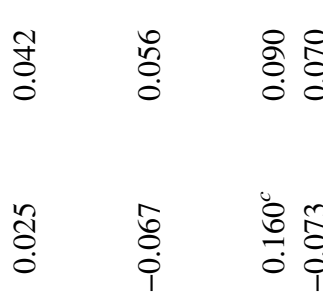

器善 棓

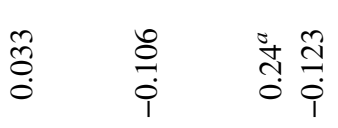

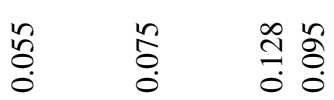

$\begin{array}{llll}\infty & n & \infty & 0 \\ 0 & 0 & 0 \\ 0 & 0 & 0 & 0 \\ 0 & 0 & 1\end{array}$

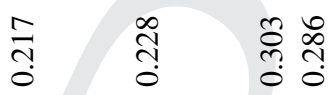

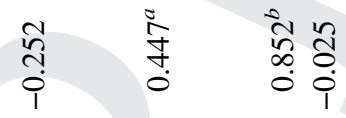

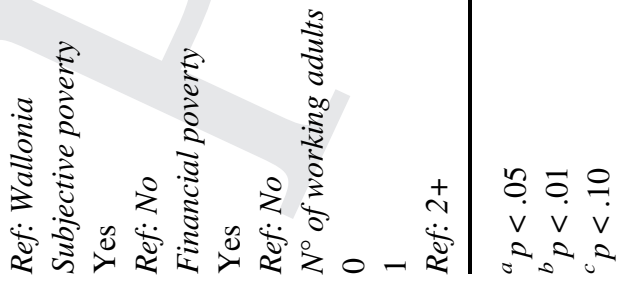


income in particular requires extensive information based in principle on households' tax declarations of the previous calendar year (to be combined if necessary across different subunits in the household). Whenever respondents raise objections against these questions or cannot retrieve the requested information, they may stop collaborating.

Which factors explain differences in response behavior between groups? Financial poverty has a significant effect on "unreachability." In addition, a separate analysis of the probability of moves between Waves 1 and 2 (not reported in detail here) showed that poor households move more frequently, which increases the risk of unreachability. ${ }^{5}$ Note, however, that this is the only type of nonresponse for which the effect of financial poverty is significant, and moreover the number of unreachable households was low (thirty-eight cases). The overall direct effect on attrition is negligable. Nevertheless, it does seem that other determinants of poverty such as the absence of income from employment, a low level of education of the household head, and residential status (tenant as opposed to owner) are significantly correlated with one or more of the nonresponse types.

For a better understanding of these findings, two focus groups were held with experienced interviewers from ADSEI. Most interviewers had extensive experience in various surveys organized by ADSEI. They also received a manual and an extensive briefing before the start of each EU-SILC wave. For our focus group interviews, four interviewers were selected from each region in Belgium (Flanders, Wallonia, and Brussels); two-thirds of them had more than four years' experience with EU-SILC.

According to the interviewers, nonresponse in poor households is related to the following factors:

- General mistrust by low-educated individuals;

- The complexity of the questionnaire (as explained above, the questions about income constitute major stumbling blocks);

- Tenants more often live in apartments or studio flats, where contact via an intercom leads to refusal more often than face-to-face contact at the door. ${ }^{6}$

The combination of statistical analyses with qualitative information from the focus groups can also contribute to a better preventive and remedial approach to nonresponse. Nonresponse can be partly avoided by (a) simplifying the questionnaires (e.g., by offering respondents encountering difficulties the possibility of skipping certain questions); (b) further refining the interviewer manual and providing better training concerning complex items (especially relating to sources of income); and (c) enlisting experienced interviewers to assist in the training of new colleagues. Experienced interviewers have developed a certain proficiency in anticipating nonresponse, in their way of making contact and their

5 This appears to be in line with other surveys. The US Census produces data on mobility rates by income and age of householder. Housing instability is much higher among the young, the poor, and couples in childrearing years.

6 One may wonder why such households cooperated in the first wave and no longer in the second wave. This may be attributable to the fact that in the latter case they already knew more about the contents and duration of the interview. 
presentation style as well as in their skill in maneuvering through difficult sections in the questionnaire.

Obviously, some degree of selective nonresponse and attrition is unavoidable. To a certain extent, nonresponse can be remedied by adjustment weights. Weights have been developed for the EU-SILC datasets, but there is still substantial room for improvement in the estimation methods, including using individual estimation models for nonresponse by wave.

\subsection{Population groups with a high risk of poverty that are not included in the EU-SILC surveys}

A second goal of our research was to examine which groups with an elevated risk of poverty were excluded from the EU-SILC at the outset. We identified a number of at-risk groups and, based on existing studies, assessed their risk of poverty. To begin with, the EU-SILC sample was drawn from the National Register, excluding collective households. Hence, some groups are explicitly not covered in the sampling frame, specifically "collective households" and households that are not included in the National Register.

Collective households include homes for elderly people, institutions, prisons, and convents/monasteries. The number of people living in such institutions is known: figures can be retrieved from the population census or from occasional publications focused on specific groups. Approximately 1.4 percent of the Belgian population live in collective households, and four-fifths of this group are elderly people. With the exception of monasteries, we can safely assume that these groups have an increased risk of poverty. Some of them may be hard to interview, but the main reasons for their exclusion are (a) that the people concerned do not live in their original (private) household, and (b) that the EU-SILC questionnaires were not designed to measure living conditions in collective households.

People who are not listed in the National Register (or related registers) are mainly undocumented immigrants, who are presumed to have a (very) high risk of poverty but their numbers are unknown. Following the 2000 regularization campaign in Belgium, the Ministry of Employment estimated the number of undocumented immigrants at 87,000 (0.8 percent of the population). Djajić (2001) mentions an estimate of 100,000, whereas Delaunay and Tapinos (1998) published the highest figure $(140,000$ or 1.3 percent of the population).

In addition to groups that are not covered by the sampling frame, some groups rarely or never stay at their legally registered address and cannot be reached at the address where they live. $^{7}$

This group includes rough sleepers and other homeless people (living in shelters, homes, or temporary dwellings), as well as caravan dwelers and itinerant groups:

7 Note that, in addition to official residence address lists, interviewer assignments include updated addresses provided by the municipal administration or (in the case of panels) updates signalled by the respondents themselves. They receive instructions regarding flexible timing of the interviews and - if the household no longer lives at the indicated address - use of informal information sources to track households. 
- 10,000 travelers, circus people, and bargees are known to ADSEI. In addition, gypsies supposedly account for more than 10,000 people.

- The number of permanent camping dwellers is estimated at 10,000 in the Walloon Region and 4,300 in the Flemish Region. However, these figures are not up to date and serious efforts are being made to transfer these households into regular housing.

- As regards homeless people, the ETHOS typology (European Typology of Homelessness) distinguishes between "rough sleepers" (who sleep in open air or in public spaces), homeless people living in shelters, households in insecure housing and households in inadequate housing. In 2003, the European Federation of National Organizations working with the homeless estimated that the two former categories (which would not be reached by EU-SILC) accounted together for 17,000 people in Belgium. There is a widespread impression that this number has increased since 2003.

Taken together, all the aforementioned groups constitute between 2.6 and 3 percent of the Belgian population. The impact of these groups on the overall (financial) risk of poverty in Belgium could lie somewhere between 0.6 and 1.7 percentage points. $^{8}$ Apart from their quantitative significance, some groups are also important because of their specific living conditions (e.g. caravan dwellers) or their extreme poverty (e.g., rough sleepers or undocumented immigrants).

\subsection{Complementary survey among hidden groups of poor people}

Due to the budget constraint of this research, we had to confine our complementary pilot survey to two selected population groups that either do not form part of the sampling frame of the EU-SILC or do not live at their official residence: rough sleepers and homeless people, and undocumented immigrants. These groups were selected because of their high level of obscurity, their relative size, and their unusually high level of deprivation. The aim of our exercise was not to count them, but rather to collect data that would allow us to compare the living conditions of these groups with those of other poor households and with the crosssection of Belgian households.

\subsubsection{Methodology}

\section{Organization of the field work}

Our survey was carried out in the spring of 2010. The strategy for the pilot relied on collaboration between the research team, a specialized interview office, advocacy groups,

8 The lower bound assumes an enhanced poverty risk (AROP definition) only among the homeless and unauthorized immigrants (72 percent among homeless people and 96 percent among undocumented immigrants - see Section 26.4) and is based on the lowest estimated number of undocumented people. The upper bound assumes a poverty risk of 30 percent among the other excluded categories and the highest estimated number of undocumented people. 
and social services working with the homeless and/or undocumented immigrants. The survey was part of a long and carefully planned process in several steps:

- We started with a study of existing (though fragmented) evidence concerning the profile and living conditions of the selected groups, particularly in the Belgian context.

- Negotiation of the purpose of statistical data collection with advocacy groups and social services was important to the success of the survey. These organizations can increase the efficiency of the data collection through feedback on the draft questionnaires and by mediating between interviewers and (potential) respondents. By the same token, they act as gatekeepers who decide to collaborate based on the perceived utility of the research (see also Olson, Vargas, and Williams, contribution on how to mobilize target groups, Chapter 29 in this volume). Our previous experience showed that social workers tend to be skeptical about research in general, and statistical research in particular. Their participation in the survey development stage improved its relevance and helped avoid mistakes, but also helped the research team overcome prejudices and resistance vis-à-vis the planned research. Overall, sixty-two organizations from the social sector (service providers, advocacy groups, and street corner workers) collaborated in the research.

- Although the content and method of the survey needed to stick as closely as possible to the design of EU-SILC, there was extensive consultation with field workers about adaptations to the questionnaire (language issues, rephrasing of questions, deletion of complex items, addition of target-group specific modules), the sampling method, and the contact procedure for the interviews.

- The team of the Combat Poverty Service carried out a "pre-pilot survey" with thirty individuals and households in order to test the revised draft of the questionnaire and to evaluate the contact procedure with respondents. This resulted in a second revision of the questionnaire and procedures. In particular, it appeared already from this pre-pilot survey that homeless people are much more accessible to interviewers than undocumented immigrants, and men more than women. We also learned that random sampling of respondents within organizations would not be feasible, due to the absence of registers and interference of language, psychological, and mental problems (such as addiction or depression).

- For the proper survey, IPSOS (the market research company which was responsible for the field work) selected interviewers with considerable experience and good social skills, and offered them a specific training coorganized with the research team. Ethnic background was not a criterion for interviewer selection.

- During the field work for the proper pilot survey, the interviewer team was continuously backed by the researchers. An extensive interviewer debriefing collected their opinions about and experience with the questionnaire and the data collection process (see below).

- The research team made a preliminary analysis of the data, both from a methodological and a substantive point of view. The main findings from this analysis are presented below.

- Finally, in order to encourage ownership of the research by stakeholders, feedback was provided to all participating parties through seminars and presentations at various locations. 
Ides Nicaise and Ingrid Schockaert

Table 26.3 Anticipated/achieved number of interviews, homeless people

\begin{tabular}{|c|c|c|c|c|c|c|c|c|}
\hline & \multicolumn{2}{|l|}{ Flanders } & \multicolumn{3}{|c|}{ Brussels } & \multicolumn{3}{|c|}{ Wallonia } \\
\hline & $91 / 141$ & & & 71 / 68 & & & 88 / 68 & \\
\hline Men & & Women & Men & & Women & Men & & Wom \\
\hline $61 / 89$ & & $30 / 52$ & $57 / 41$ & & $14 / 27$ & $64 / 38$ & & $24 / 30$ \\
\hline Rough sl. & & Shelter & Rough sl. & & Shelter & Rough sl. & & Shelter \\
\hline $13 / 19$ & & $78 / 120$ & $11 / 19$ & & $60 / 49$ & $13 / 26$ & & $75 / 42$ \\
\hline$<30$ & $30-50$ & $>50$ & $<30$ & $30-50$ & $>50$ & $<30$ & $30-50$ & $>50$ \\
\hline $47 / 50$ & $31 / 66$ & $13 / 21$ & $30 / 15$ & $29 / 37$ & $12 / 16$ & $37 / 17$ & $36 / 39$ & $15 / 10$ \\
\hline
\end{tabular}

\section{Sampling and response}

The target was to interview 250 homeless people and 250 undocumented immigrants. The two-stage sampling process, beginning with a selection of intermediaries, obviously involved a risk of missing the most marginalized people in our target groups - particularly rough sleepers. Therefore, 15 percent of the interviews were conducted in the street, in stations, or abandoned buildings, and another 5 percent of the respondents were contacted through a snowball method. On the other hand, we opted for collaboration with thirdsector organizations because in this way we expected to have easier access to a sufficient number of respondents, especially among undocumented immigrants who appeared to be the hardest to reach. Our expectations were met on this point, because the overall "nonresponse" is attributable to the unreachability of targeted persons rather than refusals or failed interviews. Of all individuals contacted for an interview, 70 percent completed the interview. ${ }^{9}$

Quota were set per region on the basis of different sources that provided approximate information: for homeless people, we benefited from registers of the associations of shelters, while for undocumented immigrants we assumed that their profile would be comparable to that of asylum seekers. Tables 26.3 and 26.4 give an overview of the anticipated and achieved quota per cell for each of the target groups.

As can be seen from the tables, the achieved numbers deviate from the anticipated figures. Homeless people appeared easier to reach in Flanders, while undocumented immigrants were hard to reach in all three regions. The female and young homeless were (presumably) underrepresented as well, whereas Asians and Eastern Europeans are poorly represented among the undocumented immigrants. Nevertheless, it remains uncertain whether the anticipated quota should be taken as reliable.

This survey can serve as a model for similar complementary surveys in the future. The following key lessons could be drawn from this experience:

9 Rates of (un)reachability could not be measured as interviews mainly occurred on the spot, in the buildings of collaborating organizations. 
Table 26.4 Anticipated/achieved number of interviews, undocumented immigrants

\begin{tabular}{llcl}
\hline \multicolumn{5}{c}{$\begin{array}{c}\text { Flanders } \\
110 / 88\end{array}$} \\
\hline Africa & America & Asia & Europe \\
$28 / 49$ & $5 / 2$ & $40 / 30$ & $37 / 6$ \\
\hline \multicolumn{5}{c}{$\begin{array}{c}\text { Brussels } \\
68 / 30\end{array}$} \\
\hline Africa & America & Asia & Europe \\
$18 / 22$ & $2 / 1$ & $25 / 3$ & $23 / 4$ \\
\hline & & Wallonia & \\
\hline Africa & America & Asia & Europe \\
$19 / 33$ & $3 / 0$ & $26 / 8$ & $24 / 11$ \\
\hline
\end{tabular}

- Triangular collaboration between the research team (watching over the scientific nature of the survey), the survey team (carrying out the hard field work), and social sector services (validating the questionnaires and liaising with respondents) is in our view an absolute condition for effectively reaching the intended target groups. The research also benefited from the mediation by the Combat Poverty Service, which has great authority among all stakeholders and facilitated collaboration.

- Admittedly, compromises were made in survey methodology. A balance was sought in the sampling between scientific criteria and practical feasibility. For example, the researchers' initial protocol to interview every $n t h$ person on a list, or every nth person entering a shelter, was soon modified to a more realistic procedure whereby persons under the influence of drugs or alcohol, or with severe psychological disorders were screened out, because this would lead to incoherent patterns of response. An alternative approach using the snowball method appeared to produce only a limited return. In the case of homeless people, snowballing was redundant because there was enough direct access to other respondents; as regards undocumented immigrants, anxiety and distrust probably explain why respondents did not refer the interviewers to their peers.

- The interviewers themselves must also be psychologically counseled so that they can cope well when faced with consequences of extreme poverty or social exclusion. Some interviewers were so overwhelmed by their respondents' misery that they wanted to provide emergency assistance; others were faced with suicide, crime, police intervention, and expulsion (see also Chapters 6, 7, and 8 in this volume). Admittedly, such incidents were insufficiently anticipated.

- Undocumented immigrants appear to be particularly hard to reach - partly as a result of language barriers and partly as a result of their fear of being caught and expelled from the 
country. In many cases, we first needed to identify the sampled person's native language, and by the time an interpreter was found the person had disappeared or refused to collaborate. The field work also coincided with a regularization campaign, which may have involved some tension and may explain the reluctance of interviewees.

\section{The questionnaire}

As mentioned earlier, the questionnaire (which was produced in Dutch, French, and English) had been carefully adapted in order to strike a balance between comparability with EU-SILC statistics and feasibility and relevance for our target groups. The challenge appeared to be greater than expected. Very poor people seem to have such a different life experience that for them a survey tuned to the average household can become surprisingly hard to answer. Many basic concepts do not exist or have a different meaning in the context of marginalized groups:

- In EU-SILC, the household is defined as a unit consisting of one or more persons, usually forming a family, who live at the same address and share their income and/or expenses. "Living at the same address" and "sharing income and/or expenses" are ambiguous concepts for homeless people, as their situation just before and after becoming homeless may differ radically (see Chapter 9, in this volume). This leads to different ways of reporting household composition. Similar difficulties arise with (undocumented) immigrants who may have different households in their home and host countries.

- As undocumented immigrants come from different parts of the world, it is not obvious how their educational degrees fit into the European classifications.

- Patterns of income are blurred for different reasons: a homeless person may be entitled to a benefit but may be unable to obtain it because s/he cannot provide proof of his/her official address; people may receive income from informal activities which may be hidden (moonlighting) or simply not foreseen in the list of income sources (begging, remuneration in kind, recycling).

- Even the definition of work is not straightforward in a context of extreme poverty. One in five male rough sleepers and homeless people and one in five undocumented immigrants have worked in the previous month. The fact that most of them still live below the poverty line not only demonstrates the precarious nature of that work (agency work, part-time, low-paid, or temporary work), but also that the link between work and pay is far from obvious. Particularly among undocumented immigrants, who are legally denied access to the labour market, work is often unpaid or remunerated in kind.

In Chapter 28 in this volume, Pan and Lubkemann elaborate on similar issues from the point of view of linguistic and cultural minorities.

Apart from interpretation problems, some questions appeared to trigger quite emotional reactions among respondents:

- Questions about household composition (and children in particular) remind respondents about situations of family breakdown, institutionalization, separation linked with migration, etc.; 
- Checklists of consumption items (TV, Internet access) used to measure material deprivation lead to 100 percent deprivation among the homeless, and are met with cynicism;

- Questions relating to administrative procedures can make respondents afraid that the survey will turn into police interrogation;

- Interviewers believe that questions about some sensitive health-related behaviors (e.g., the use of alcohol or sleeping pills) are not always answered truthfully.

All these issues demonstrate the importance of a well-conceived interviewer training, extensive written guidelines, and scientific as well as psychological support for the interviewer team.

On the other hand, the adaptation of the questionnaire also provided opportunities to include specific questions that are particularly relevant for the selected target groups. For homeless people, we included a few questions about mental health and access to sanitary accommodation. The survey revealed lack of access to potable water, toilet, or shower in their place of residence, as well as problems of lack of sleep, loneliness, and anxiety related to the use of alcohol or narcotics. As for undocumented immigrants, a specific module was included concerning their administrative and legal status, contacts with police, etc.

\subsection{Lessons for EU-SILC}

Given the importance attached to EU-SILC as an instrument to monitor the effectiveness of antipoverty policies, the key message from our research is that this instrument overlooks some of the most excluded groups and underestimates overall poverty rates, due to a combination of sampling and content issues. The underestimation of the poverty rate in Belgium may be as large as 1.7 percentage points (not including the nonresponse bias). Moreover, our complementary survey among homeless people and undocumented immigrants illustrates that these excluded groups are likely to experience the most severe forms of deprivation. Not only do the vast majority of these households live below the at-risk-ofpoverty threshold (72 percent of rough sleepers and homeless people and 96 percent of undocumented immigrants) but most of them live far below it. Financial income is extremely low, especially among undocumented immigrants. Both target groups also show material deprivation indices of 100 percent.

Several types of measures are needed to remedy these sources of bias: re-weighting, extension of the sampling frame, and adaptations to the questionnaires.

Re-weighting is probably the simplest part of the correction. We showed how selective nonresponse in the initial sample as well as selective attrition can be corrected for. The extension of the sampling framework to hard-to-survey groups is more difficult, simply because register data on some groups is missing. We would therefore recommend to conduct specific small stratified surveys among hard-to-reach groups with an enhanced poverty risk and to integrate the results with the "mainstream" survey by means of a weighting procedure. Our complementary survey points to the feasibility of such specific additions to the EU-SILC. The fact that this has worked in two target groups that are very hard to reach suggests that it might also work with other target groups. Obviously, such additional surveys involve serious 
efforts and fairly high marginal costs. Policymakers need to decide whether it is preferable to invest in yearly additional surveys or in periodic ad hoc modules. We recommend at least (a) that this type of survey also be carried out among the other population groups that currently fall outside the EU-SILC samples (those in "collective households," caravan dwellers, itinerant populations, etc.); (b) that such surveys should take place periodically, so as to allow for systematic monitoring of progress made; and (c) that the methodology should be replicated at EU level for the purpose of cross-national comparisons.

Another lesson from our nonresponse analysis relates to the contents of the EU-SILC survey: there are strong indications of a tradeoff between the extent and precision of the collected information and the representativeness of the survey for population groups with an enhanced risk of poverty. The underrepresentation of poor households appears to be due at least partly to the complexity of the questionnaire. Hence, it may be desirable to include simplified modules, particularly in relation to income data, for respondents who lack the skills (or indeed the tools) to analyse their yearly household income in detail - even in faceto-face interviews with support from experienced interviewers.

Furthermore, our experience showed that even a well-designed standard questionnaire may lose a lot of its transparency when used in exceptional circumstances. Basic concepts such as household, income, educational attainment, housing, and work need to be clearly defined and adapted to all circumstances. Interviewers need to receive clear guidelines and adequate training in order to minimize nonresponse or biased answers.

\section{References}

De Keulenaer, F., \& Levecque, K. (2004). Mood and socio-economic status bias in survey nonresponse: results from an 11-wave panel. In C. van Dijkum, J. Blasius, \& C. Durand (eds.), Proceedings of the 6th International Conference on Social Science Methodology: Recent Developments and Applications in Social Research Methodology (pp. 1-21). Amsterdam: Netherlands Institute for the Social Sciences (SISWO).

Delaunay, D., \& Tapinos, G. (1998), La mesure de la migration clandestine en Europe, vol. I: Rapport de Synthèse. Eurostat Working Papers: Population and Social Conditions. Luxembourg: Eurostat.

Djajić, S. (2001). Illegal immigration: trends, policies and economic effects. In S. Djajić (ed.), International Migration: Trends, Policies and Economic Impact (pp. 37-61). London: Routledge.

European Commission. (2013). Social Europe. Current Challenges and the Way Forward. Annual Report of the Social Protection Committee (2012). Brussels: Directorate General Employment and Social Affairs.

Groves, R. M., \& Couper, M.P. (1998). Nonresponse in Household Interview Surveys. New York: John Wiley \& Sons.

Heerweegh, D., Abts, K., \& Loosveldt, G. (2007). Minimizing survey refusal and noncontact rates: do our efforts pay off? Survey Research Methods, 1(1) 3-10. 